\title{
Fibroadenoma of the Ectopic Axillary Breast Tissue: Sonographic Appearances
}

\author{
Xueyu Rong, Qiang Zhu*, Wenxiu Jia, Teng Ma, Yaqi Fang, Yajing Zhou, Xixi Wang \\ Department of Diagnostic Ultrasound, Beijing Tongren Hospital, Capital Medical University, Beijing, China \\ Email: "quhutr@sina.cn
}

Received 11 September 2014; revised 11 October 2014; accepted 5 November 2014

Copyright (C) 2014 by authors and Scientific Research Publishing Inc.

This work is licensed under the Creative Commons Attribution International License (CC BY). http://creativecommons.org/licenses/by/4.0/

c) (i) Open Access

\begin{abstract}
Ectopic breast tissue is reported to occur in $0.4 \%$ - $6 \%$ of women. Breast neoplasms may develop in ectopic breast tissue, as in eutopic breast tissue. The most frequent condition in ectopic breast is breast cancer. Fibroadenomas of ectopic breast tissue have been reported, but are rare. We report two cases of fibroadenomas of ectopic axillary breast tissues. The sonographic appearance of the nodules was spherical and hypoechoic. We found the component of breast tissue near the nodule. It is important to diagnose fibroadenomas of ectopic breast tissue before a histologic examination.
\end{abstract}

\section{Keywords}

Fibroadenoma, Ultrasound, Ectopic Breast

\section{Introduction}

Ectopic breast tissue (EBT) is found in $0.4 \%$ - $6 \%$ of all women, and occurs more commonly in Asian women [1]. During the fifth week of gestation, primitive mammary ridges are formed bilaterally along the milk line in the embryo, extending from the axilla to the inner thigh. Ectopic mammary glands consist of tissues resulting from incomplete embryologic regression of mammary ridges. Ectopic mammary glands disappear under normal conditions, with the exception of the thoracic region where normal breast tissues grow. EBT is frequently located along the milk line, but can occasionally be detected in unusual locations, such as the axilla, scapula, thigh, and vulva [2] [3]. The axilla is the most common site involved, accounting for $60 \%-70 \%$ of the unusual malposition. All of the pathologic processes that affect normally-positioned breasts might occur in EBT in despite of a low incidence. Only a few of cases with EBT tumors have been reported [3]-[5]. The purpose of the current paper was to report two patients with EBT fibroadenomas localized in the axillae.

\footnotetext{
*Corresponding author.
} 


\section{Case Reports}

Case 1: A 41-year-old female palpated a cherry-sized nodule in the left axilla without any symptoms, but enlargement in size 3 months before admission to our hospital. The physical examination revealed a subcutaneous nodule in the left axilla, measuring $2 \mathrm{~cm}$ in diameter. The nodule was smooth and the margins were clear. The nodule was not adherent to the skin and was non-tender. No nodules were palpable in the breasts bilaterally, the contralateral axilla, and the bilateral supraclavicular fossae.

On sonographic scanning with a Logiq 9 scanner and a M12L type linear-array probe made (GE Medical Systems, Milwaukee, WI, USA), a low echoic nodule was demonstrated in the left axilla, $2.1 \times 1.7 \mathrm{~cm}$ in size, with a clearly circumscribed and slightly lobulated margin, and a homogeneously solid texture. A thin layer of echogenic tissue resembling normal mammary tissue was identified around the lesion. Increased blood flow signals with spot and short club shapes were noted on color Doppler images. A benign lesion of the left axilla was diagnosed sonographically (Figure 1(a) and Figure 1(b)). A surgical resection was subsequently performed.

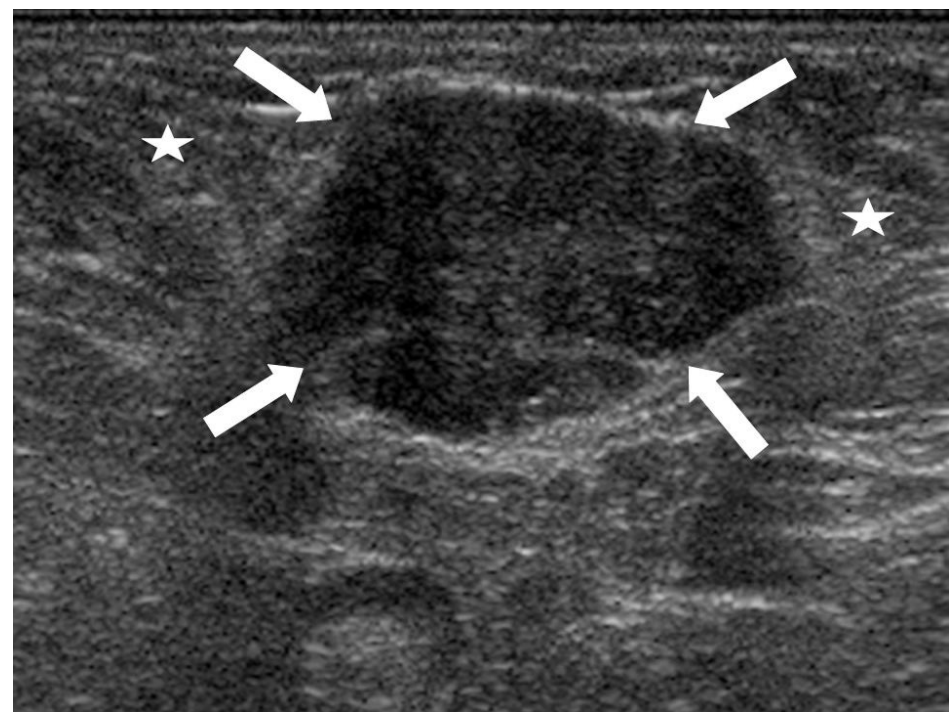

(a)

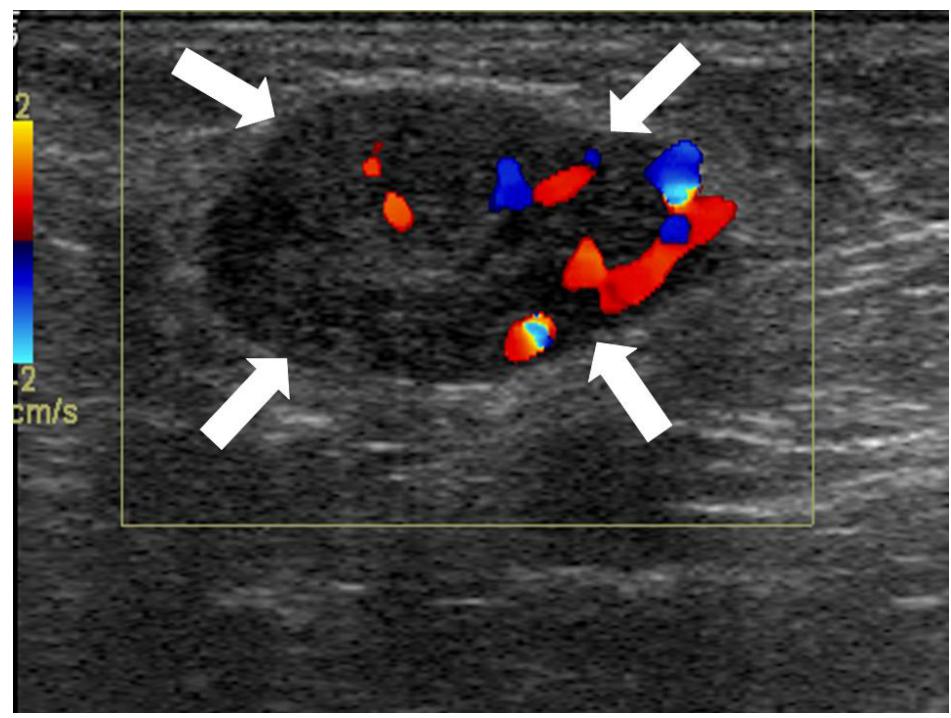

(b)

Figure 1. (a) Ultrasonography showed a homogeneous and hypoechoic mass in the left axilla (arrow). The tiny tissue, which had an echogenic appearance resembling breast tissue, was adjacent to the nodule (star); (b) Increased vascularity was seen with color Doppler. 
The microscopic examination yielded a diagnosis of a fibroadenoma based on an adenomatous component of single or fused glandular ducts accompanied by proliferation of connective tissue (Figure 2). Close to the nodule, normal mammary gland tissue was identified. The patient underwent a 5-month follow-up with no recurrence of the tumor.

Case 2: A 37-year-old female found one peanut-sized nodule in the left axilla during pregnancy 8 years earlier. There was scant secretion from the nodule during lactation. The nodule has caused intermittent discomfort, although it has not enlarged since the time of detection. The physical examination showed that the nodule was slightly hard and mobile. A small hole was noted on the surface skin superficial to the nodule. Mammographically, an ovoid and high-density nodule was demonstrated in the left axilla with a well-defined, but lobulated margin in a lateral-oblique image, with no microcalcifications shown (Figure 3). On ultrasound images a smoothly marginated and homogenously hypoechoic nodule was shown in the left axilla. Some enlarged blood flow signals were seen on color Doppler image (Figure 4(a) and Figure 4(b)). A benign tumor was considered. The nodule was completely excised. The diagnosis of a fibroadenoma from EBT was made based on pathologic evaluation (Figure 5).

\section{Discussion}

Embryonic mammary ridges of ectodermal thickening extend vertically along the ventral surface of the body from the anterior axillary folds to the inside of the inguinal folds. In the human embryo, the mammary ridges regress, except in the pectoral region. Persistence of tissue anywhere along the ridge can result in supernumerary breast tissue. EBT can present as a mass anywhere along the course of the embryologic mammary streak, but is most frequently found in the axilla [6].

The mammographic features were best demonstrated on lateral-oblique and cranio-caudal views, and appeared as dense or fatty parenchyma [7]. On ultrasound, EBT is visualized as an echogenic area with the same appearance as normal glandular tissue.

When a nodule or mass is detected in the axillary fossa, the pathologic classification considered includes enlargement of lymph nodes, lipomas, neuromas, skin lesions, such as epidermal inclusion cysts, and lesions arising from EBT. EBT has the same hormonal changes as normal breast tissue. Hence, a patient with EBT often becomes symptomatic during puberty, pregnancy, and lactation, exhibiting regional swelling, tenderness, and sometimes secretions. These symptoms during menses or pregnancy frequently result in patients seeking physician evaluation and help in the diagnosis EBT. Indeed, a solitary nodule without symptoms in the axilla is often

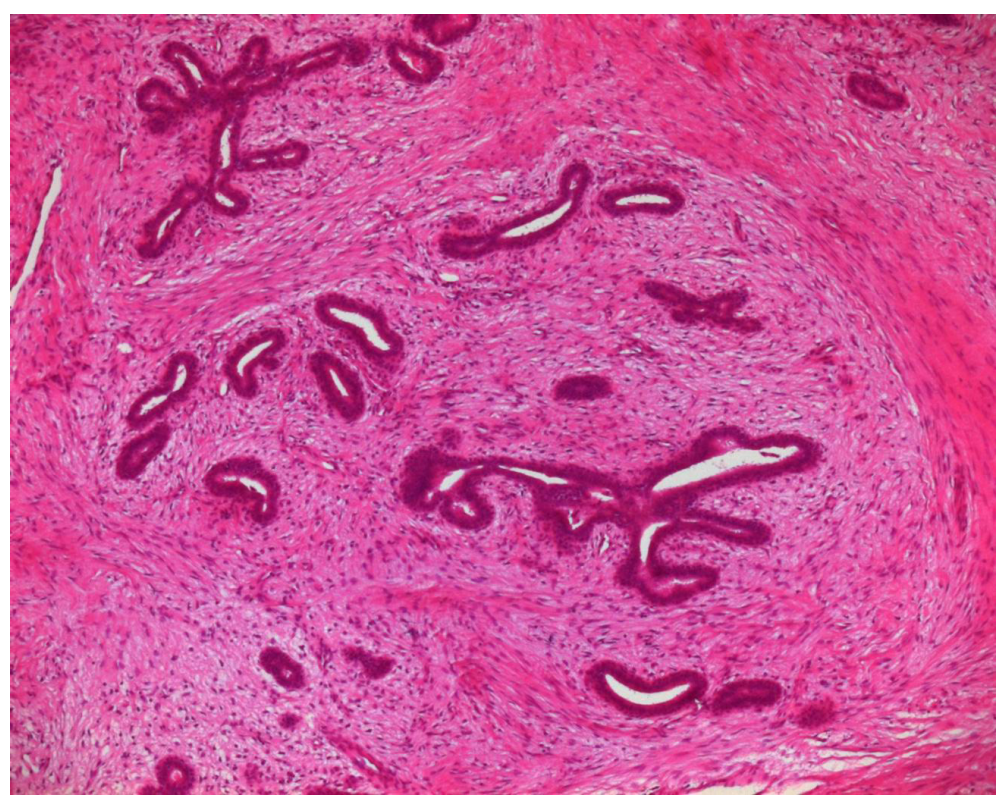

Figure 2. Histologic specimen shows adenoid formations mixed with areas of fibrosis and proliferating (hematoxylin-eosin stain; original magnification $\times 5$ ). 


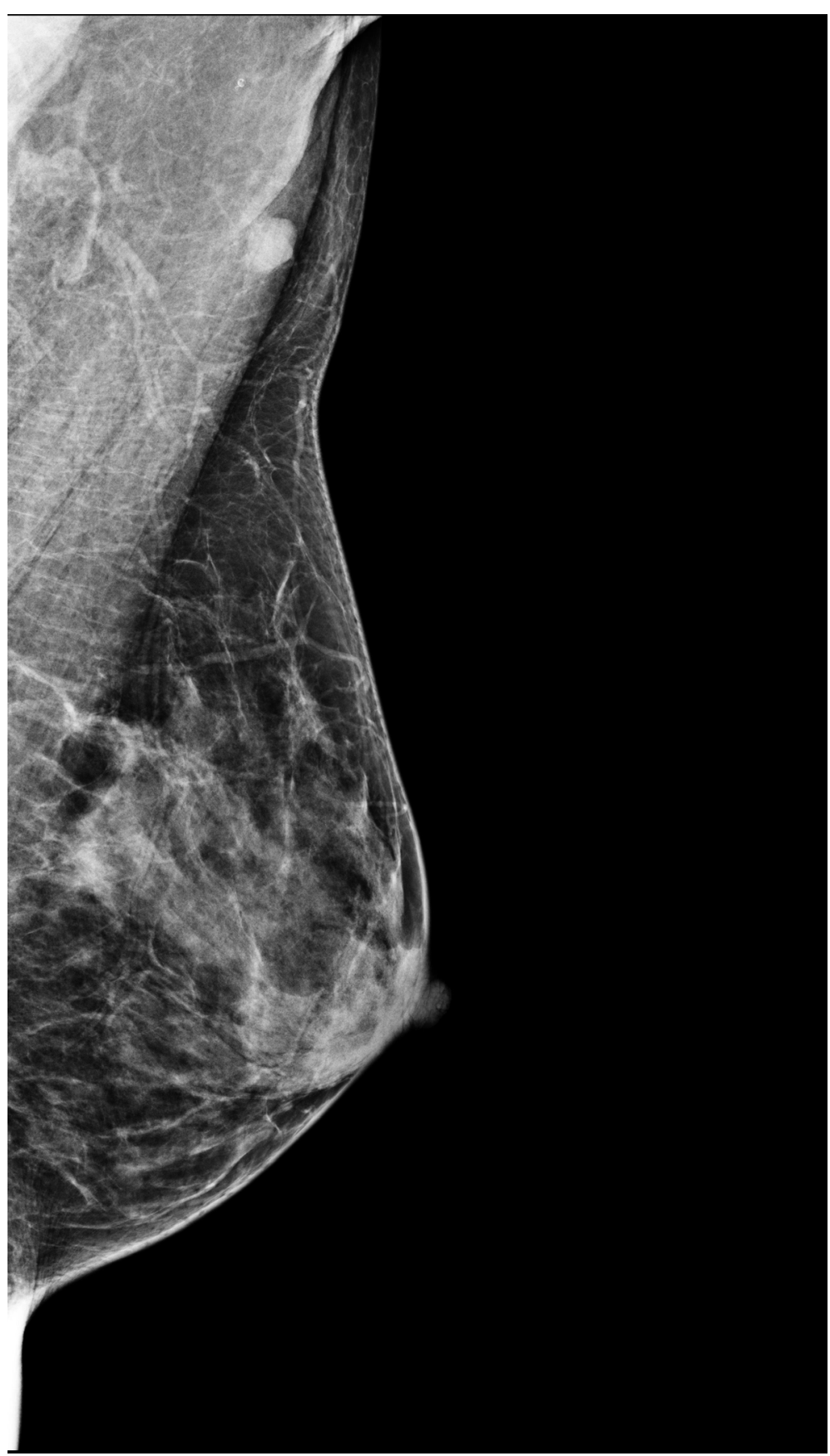

Figure 3. Mammography demonstrated an ovoid density in the left axilla with well-defined margins.

imperceptible. It is difficult to make the diagnosis of a nodule with respect to classification and benign or malignant nature.

With ultrasound, it is crucial to determine whether or not the breast tissue surrounding the axillary lesion is present or not in the diagnosis of EBT [8]. EBT is typically seen as an echogenic area resembling normal glandular tissue [9]. EBT is located in the subcutaneous tissue and deep dermis of the skin.

EBT can be affected by the same pathologies as eutopic breast tissue, i.e., fibrocystic changes, mastitis, intraductal papillomas, abscesses, fibroadenomas, carcinomas, and phyllodes tumor [3]-[5] [10]. The diagnosis of these conditions in EBT is similar to those diagnoses occuring in breasts with normal thoracic locations. 


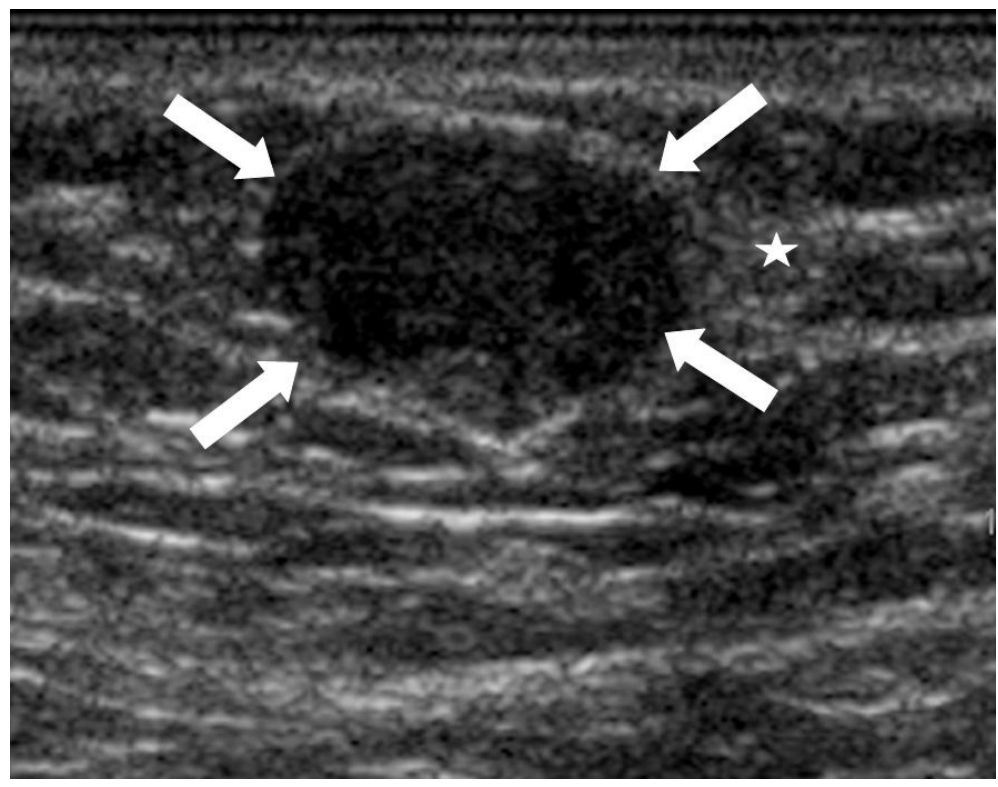

(a)

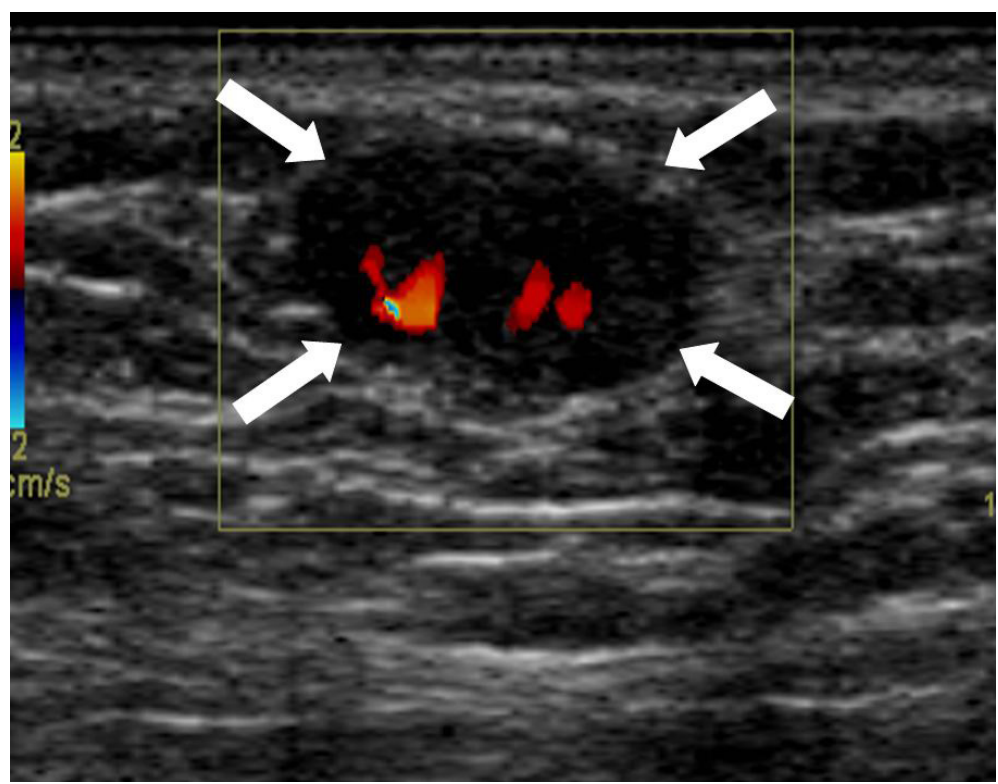

(b)

Figure 4. (a) Ultrasound showed a smoothly marginated homogenously hypoechoic nodule (arrow). The tiny tissue, which had an echogenic appearance resembling breast tissue, was adjacent to the nodule (star); (b) Increased vascularity was seen with color Doppler.

Fibroadenomas are a frequent cause of nodules in young women, with the highest incidence between 20 and 30 years of age. Fibroadenomas are rarely described in EBT. Sawa et al. [8] reported a case involving a fibroadenoma in an axillary accessory breast in a 41-year-old woman who presented with a right axillary mass associated with 5 small nodules in the normally situated breast. Coras et al. [11] reported a fibroadenoma in the axillary accessory breast of a 23-year-old woman which was histologically-identical to the fibroadenomas existing in the breast. Differential diagnosis of an axillary tumor should include EBT. The diagnosis of EBT is strongly suggested by a history of cyclic changes during the menstrual period or by the initial appearance during pregnancy. 


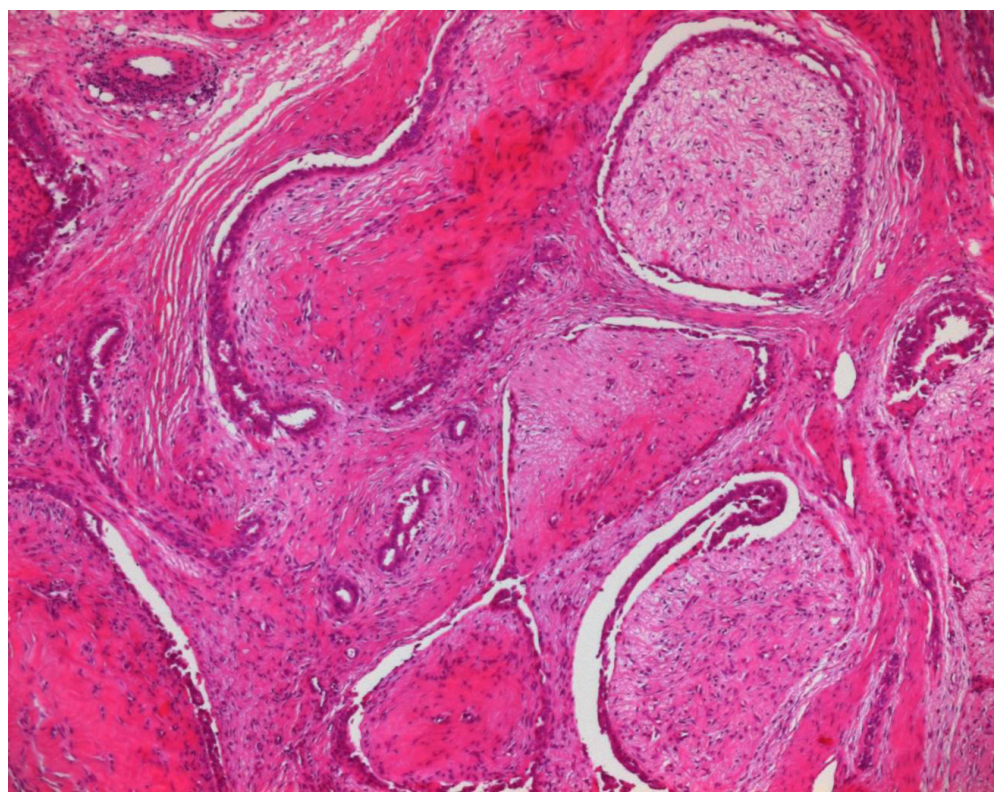

Figure 5. Histologic examination of the axillary nodule showing fibroadenomas of EBT (hematoxylin-eosin stain; original magnification $\times 5$ ).

In our cases, the patients did not complain of any pain or tenderness involving the mass lesion associated with menstruation. Some features were revealed on ultrasound. The mass appeared to be well-circumscribed, homogeneous, and hypoechoic. Sonography showed increased echotexture of normal breast tissue adjacent to the nodule, leading to a correct diagnosis of an ectopic breast fibroadenoma.

In our cases, we first ruled out malignant disease because of the clear margins. Enlargement of lymph nodes is often present as a hyperechoic hilum. Lipomas are often isoechoic or hyperechoic to the surrounding fat or echogenic. Neuromas are derived from the sheaths of peripheral nerves. Neuromas are usually located intracutaneously, and less frequently subcutaneously. The sonograms depicting epidermal inclusion cysts show a smoothly marginated, complex-echo mass with good through-transmission, and extension of the mass into the dermal layer.

In conclusion, a lesion arising from EBT should be considered when the appearance of an echogenic area resembling normal glandular tissue is present on ultrasound images. A fibroadenoma of EBT was demonstrated as homogeneous and hypoechoic mass with clear margins.

\section{Acknowledgements}

We are grateful to Professor HongGang Liu, Department of Pathology, Beijing Tongren Hospital, Capital Medical University, for his help and advice with these cases.

\section{References}

[1] Gilmore, H.T., Milroy, M. and Mello, B.J. (1996) Supernumerary Nipples and Accessory Breast Tissue. South Dakota Journal of Medicine, 49, 149-151.

[2] Greer, K.E. (1974) Accessory Axillary Breast Tissue. Archives of Dermatology, 109, 88-89. http://dx.doi.org/10.1001/archderm.1974.01630010064017

[3] Hong, J.H., Oh, M.J., Hur, J.Y. and Lee, J.K. (2009) Accessory Breast Tissue Presenting as a Vulvar Mass in an Adolescent Girl. Archives of Gynecology and Obstetrics, 280, 317-320. http://dx.doi.org/10.1007/s00404-008-0905-z

[4] Oshida, K., Miyauchi, M., Yamamoto, N., Takeuchi, T., Suzuki, M., Nagashima, T., et al. (2003) Phyllodes Tumor Arising in Ectopic Breast Tissue of the Axilla. Breast Cancer, 10, 82-84. http://dx.doi.org/10.1007/BF02967630

[5] Evans, D.M. and Guyton, D.P. (1995) Carcinoma of the Axillary Breast. Journal of Surgical Oncology, 59, 190-195. http://dx.doi.org/10.1002/jso.2930590311

[6] Bertschinger, K., Caduff, R. and Kubik-Huch, R.A. (2000) Benign Intramammary and Axillary Lesions Mimicking 
Malignancy. European Radiology, 10, 1029-1030. http://dx.doi.org/10.1007/s003300051058

[7] Adler, D.D., Rebner, M. and Pennes, D.R. (1987) Accessory Breast Tissue in the Axilla: Mammographic Appearance. Radiology, 163, 709-711. http://dx.doi.org/10.1148/radiology.163.3.3575719

[8] Sawa, M., Kawai, N., Sato, M., Takeuchi, T., Tamaki, T. and Oura, S. (2010) Fibroadenoma of the Axillary Accessory Breast: Diagnostic Value of Dynamic Magnetic Resonance Imaging. Japanese Journal of Radiology, 28, 613-617. http://dx.doi.org/10.1007/s11604-010-0466-5

[9] Yang, W.T., Suen, M. and Metreweli, C. (1997) Mammographic, Sonographic and Histopathological Correlation of Benign Axillary Masses. Clinical Radiology, 52, 130-135. http://dx.doi.org/10.1016/S0009-9260(97)80106-7

[10] Dzodic, R., Stanojevic, B., Saenko, V., Nakashima, M., Markovic, I., Pupic, G., et al. (2010). Intraductal Papilloma of Ectopic Breast Tissue in Axillary Lymph Node of a Patient with a Previous Intraductal Papilloma of Ipsilateral Breast: A Case Report and Review of the Literature. Diagnostic Pathology, 5, 17-20. http://dx.doi.org/10.1186/1746-1596-5-17

[11] Coras, B., Landthaler, M., Hofstaedter, F., Meisel, C. and Hohenleutner, U. (2005) Fibroadenoma of the Axilla. Dermatologic Surgery, 31, 1152-1154. http://dx.doi.org/10.1097/00042728-200509000-00015 
Scientific Research Publishing (SCIRP) is one of the largest Open Access journal publishers. It is currently publishing more than 200 open access, online, peer-reviewed journals covering a wide range of academic disciplines. SCIRP serves the worldwide academic communities and contributes to the progress and application of science with its publication.

Other selected journals from SCIRP are listed as below. Submit your manuscript to us via either submit@scirp.org or Online Submission Portal.
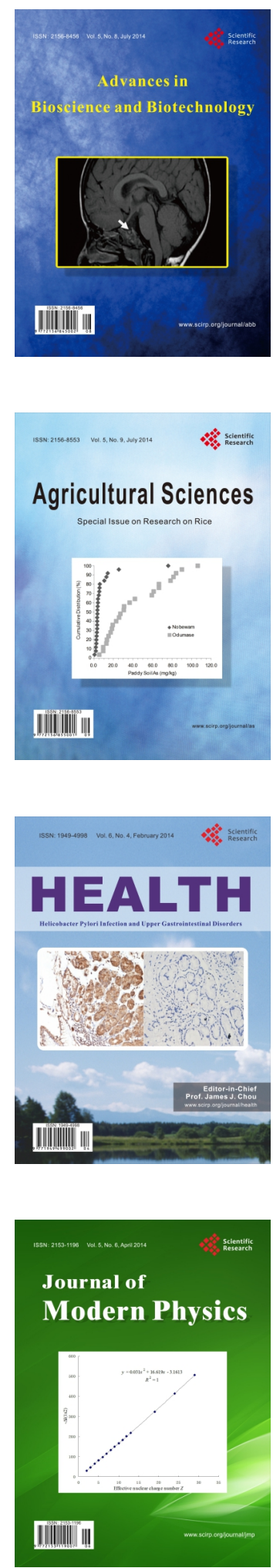
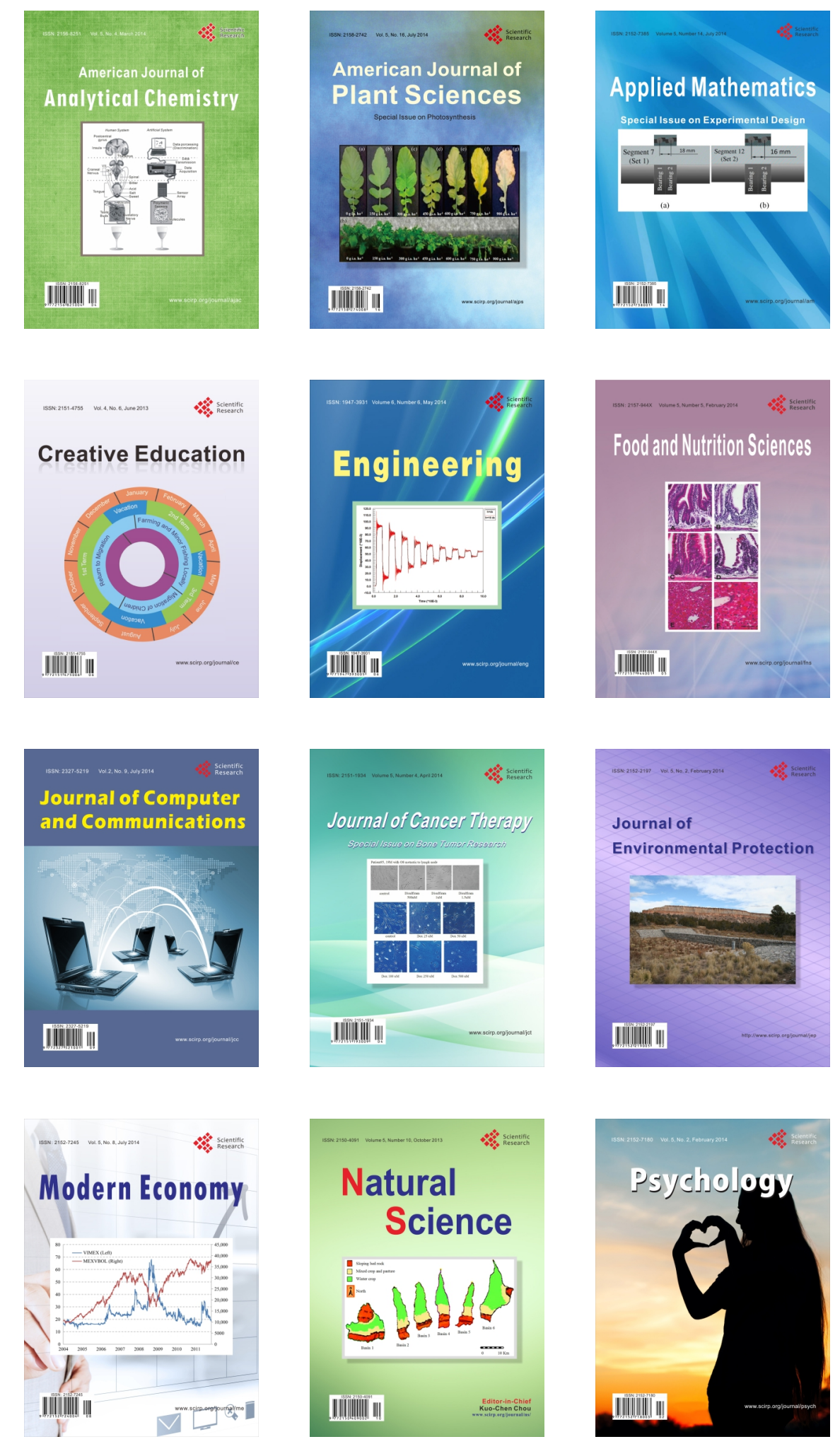